\title{
Strabismus shows the way
}

Embryonic cellular movements are dauntingly complex. A new study shows that an evolutionarily conserved pathway keeps cells pointed in the right direction.

wild type

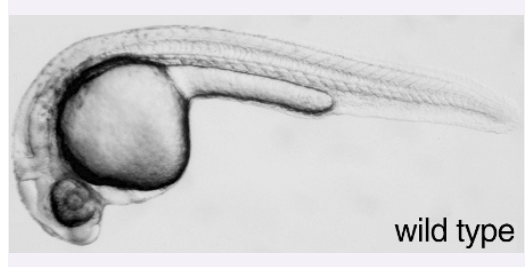

Is there a better subject for time-lapse photography than embryogenesis? By condensing the three-dimensional complexity of development into a few seconds, moviemakers have shown the embryo to be a shape-changing marvel. In recent years, geneticists have begun to chip away at the molecular pathways that underlie morphogenesis. Writing in Nature Cell Biology, Jason Jessen and colleagues ${ }^{1}$ describe the latest progress in the genetic dissection of the embryonic cellular movements known as convergent extension.

The vertebrate fertilized egg begins life as a sphere that soon becomes an elongated and visibly polar embryo. This transformation is powered in part by the stereotypical movements of a subset of cells during gastrulation. These cells first migrate from lateral regions toward the dorsal midline (convergence), and then intercalate between one another, thereby narrowing the assemblage of cells along one axis and extending it along the perpendicular axis (extension).

Recent evidence suggests that vertebrate orthologs of the Drosophila melanogaster

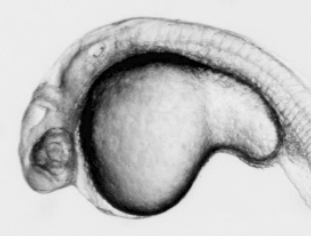

tri

Images courtesy of Jason Jessen (Vanderbilt University)

gene Strabismus (Stbm), encoding a transmembrane protein, might be involved in convergent extension in vertebrate embryos. In D. melanogaster, Stbm is known to regulate the polarity of structures in the insect cuticle (known as planar cell polarity) through the non-canonical Wnt signaling pathway ${ }^{2}$. In Xenopus laevis, overexpression of $\mathrm{Stbm}$ causes severely shortened trunk structures, consistent with a planar cell polarity or convergentextension phenotype ${ }^{3,4}$. In the zebrafish Danio rerio, inhibition of Stbm activity leads to a reduction in anterior neural markers, again suggesting that it has a role in mediating cell movements during gastrulation ${ }^{5}$.

Jessen et al. ${ }^{1}$ now provide compelling genetic evidence that Stbm regulates convergent extension in zebrafish. They show by positional cloning that the zebrafish trilobite (tri) mutant (pictured here), which has defects in gastrulation movements and migration of hindbrain neurons, is allelic with $S t b m$. A series of tri alleles was found to have disruptions of the Stbm coding region, and injection of Stbm mRNA partially rescues tri embryos. More impressive, Jessen et al. ${ }^{1}$ provide new insight into the precise role of Stbm. By examining the length-towidth ratio of migratory ectodermal cells in wildtype and tri embryos, they show that the ratio is reduced in tri embryos, as is the mediolateral alignment of these cells. Moreover-and there are time-lapse movies to prove this-the speed with which tri cells migrate to the dorsal midline is reduced. Finally, the authors show that hindbrain neurons in tri embryos cannot maintain the polarized orientation that is a prerequisite for directed migration. In other words, cells are aimless without Stbm.

As noted in a recent review ${ }^{2}$, this growing body of evidence suggests that the planar cell polarity and convergent-extension pathways are conserved in vertebrates, and in a range of animal phyla. Of special note is the mouse ortholog of Strabismus, Ltap, which is mutated in the classical neural tube mutant Loop-tail ${ }^{6}$. Although Loop-tail has received a lot of attention as a model for spina bifida and other neural tube anomalies in humans, Ltap homozygotes have all of the other features of a convergent-extension phenotype, including short anteroposterior axes and wide notochords.

-Alan Packer

1. Jessen, J.R. et al. Nature Cell Biol. 4 (2002); advance online publication, 8 July 2002 (doi:10.1038/ncb828).

2. Wallingford, J.B., Fraser, S.E. \& Harland, R.M. Dev. Cell 2, 695-706 (2002).

3. Darken, R.S. et al. EMBO J. 21, 976-985 (2002).

4. Goto, T. \& Keller, R. Dev. Biol. 247, 165-181 (2002).

5. Park, M. \& Moon, R.T. Nature Cell Biol. 4, 20-25 (2002)

6. Kibar, Z. et al. Nature Genet. 28, 251-255 (2001). 